\title{
DOCTRINA SOCIAL DE LA IGLESIA CATÓLICA: TRASCENDENCIA Y DERECHO EN EL CONCEPTO DE LA DIGNIDAD HUMANA*
}

\author{
Adão de Souza Pires* \\ Centro Universitário Eurípides de Marília - UNIVEM, Brasil \\ padreadaosouza@hotmail.com
}

Lafayette Pozzoli*

Pontifícia Universidade Católica de São Paulo - PUC, Brasil

lafayette@lafayette.pro.br

Gilmar Siqueira ${ }^{* * * *}$

Universidade Federal do Pará - UFPA, Brasil

gilmarsiqueira126@gmail.com

\begin{abstract}
*Este artículo es un fragmento de la disertación de Máster de Adão de Souza Pires (2018, p. 116) del autor, defendida en el Programa de Máster en Derecho de la Fundación de Enseñanza "Eurípides Soares da Rocha", mantenedora del Centro Universitário Eurípides de Marília - UNIVEM. El título de la disertación en portugués se titula "A dignidade da pesssoa humana: historicidade, conceito e transcendência - Um estudo a respeito das Encíclicas Sociais Católicas em paralelo com a dogmática jurídica". Director: Prof. Dr. Oswaldo Giacóia Júnior.

${ }^{* *}$ Máster en Derecho por el Centro Universitário Eurípides de Marília - UNIVEM. Profesor en el Instituto Filosófico Reina de la Paz, institución perteneciente a la Iglesia Católica en Jacarezinho, Paraná. Sacerdote. Licenciado en Filosofía (2001) por la Universidad San Francisco, en São Paulo. Licenciado en Derecho (2008) por la Facultad de Jaguariaíva, en Paraná. Especialista en Cultura y Medios de Comunicación (2008) por la PUC, en São Paulo.
\end{abstract}

\footnotetext{
*** Postdoctor en Filosofía del Derecho y del Estado por la Universidad "La Sapienza" (Roma, Italia). Doctor y Máster en Filosofía del Derecho por la PUC/SP. Es profesor y fue jefe de Gabinete en la PUCSP. Abogado. Consultor evaluador del INEP/MEC para Cursos Jurídicos. Líder del Grupo de Pesquisa GEDs "Direitos Fundamentais à Luz da Doutrina Social" - Derecho y Fraternidad - PUC-SP. Miembro del Consejo Editorial de la Revista EM TEMPO y de las editoriales Letras Jurídicas y Instituto Memória. Fue Profesor Asistente en el Curso de Teoría General del Derecho, ministrado por el saudoso Profesor André Franco Montoro - Postgrado PUC-SP. ORCID: https://orcid.org/0000-0001-7512-7549.
}

**** Doctorando en Derecho por la Universidad Federal de Pará y magister en Derecho por el Centro Universiterio Eurípides de Marília - UNIVEM.. ORCID: https://orcid.org/0000-0002-0042-4984. 
Resumen: El presente artículo trata de la cuestión de la dignidad de la persona humana desde la óptica trascendente de su concepto. Eso quiere decir que, encontrado un concepto firme y sólido para la dignidad de la persona humana, sea por la Doctrina Social de la Iglesia, sea por la doctrina del derecho civil, tales instituciones no se pararon en el concepto a que llegaron en el transcurso de la historia, aunque el concepto se haya manifestado como completo, profundo y necesario. Por consiguiente, ambas instituciones fueron más allá de su propia doctrina y dejaron un legado todavía superior al concepto de dignidad humana. La Doctrina Social de la Iglesia llega a la trascendencia de su concepto añadiendo elementos sobrenaturales profesados por la fe católica. El derecho, partiendo del principio del derecho a la vida como origen de todos los demás derechos, presenta un concepto de persona que sobrepasa la individualidad y proyecta hacia la sociedad una elaboración de principios que muestran que la persona humana es superior a cualquier otra consideración social; y no es la sociedad la que da dignidad a la persona, sino que la persona humana es quien orienta la sociedad en la consecución del bien común y en la garantía de los derechos individuales. La metodología de esta investigación fue una búsqueda bibliográfica y documental por el método analítico-comparativo.

Palabras clave: Doctrina Social de la Iglesia, Dignidad de la Persona Humana, Trascendencia; Iglesia y Derecho.

\title{
SOCIAL DOCTRINE OF THE CATHOLIC CHURCH: TRANSCENDENCE AND LAW IN THE CONCEPT OF HUMAN DIGNITY
}

\begin{abstract}
The article presented here addresses the question of the dignity of the human person from the perspective of the transcendence of its concept. This means that having found a firm and solid concept for the question of the dignity of the human person, whether through the Social Doctrine of the Church or the Doctrine of Civil Law, these two institutions have not slopped on the concept they have reached in the course of history, although this concept has manifested itself as complete, profound and necessary. As a result, both institutions went beyond their own doctrine and left an even greater legacy for the concept of human dignity. The Church's Social Doctrine transcends its concept by placing supernatural elements that the Catholic faith professes. The Law, based on the principle of the right to life as the origin of all other rights, presents a concept of a person that transcends the individuality of the human person and projects to society an elaborate of principles that show that the human person is superior to any other social consideration where it is not society that gives dignity to the human person, but it is the human person that guides society in achieving the common good and in guaranteeing individual rights.
\end{abstract}


The methodology of the work consisted of a bibliographic and documentary research using the analytical-comparative method.

Keywords: Social Doctrine of the Catholic Church; Humanism; Dignity of the Human Person; Transcendence; Church and Law.

\section{Introducción}

Para empezar, es menester indicar lo que se entiende por trascendencia en este artículo. Por trascendencia se pretende afirmar una realidad de algo que se identifica por un concepto determinado. Sin embargo, ese algo no permanece solo en su concepto original, sino que se eleva hacia una esfera superior, trascendente. De ahí el concepto de trascendencia. Diciéndolo en lenguaje corriente, trascendencia es la elevación de un concepto o de una realidad hacia una dimensión superior y más perfecta que la original.

La Iglesia Católica, en sus documentos pastorales, también llamados sociales, especialmente en sus encíclicas, ofrece una contribución importante a la sociedad civil y al derecho en la conceptualización de la dignidad de la persona humana y en la consecución de prácticas que hagan viable y concreta la consumación de los derechos a ella inherentes. Aunque no solo pretende permanecer en ese ámbito, pues su misión prospecta hacia una realidad más alta, superior, trascendente.

Así, pues, habiendo desarrollado la argumentación y doctrina acerca de la persona humana, especialmente fundamentada en la filosofía, la Iglesia Católica va más allá y presenta el sentido más grande y más profundo de esa dignidad humana. Es lo que se pretende tratar en este artículo bajo el término trascendencia.

Con ese propósito, en el artículo se indagará en los documentos de la Doctrina Social de la Iglesia Católica elementos que auxilien a aclarar el concepto de transcendencia para una mejor comprensión del concepto de la dignidad de la persona humana. Cabe señalar que la presente investigación se ha llevado a cabo a través del método de abordaje hipotético-deductivo, el procedimiento comparativo, la técnica de documentación indirecta y la investigación tanto bibliográfica (libros y periódicos jurídicos) como documental (legislaciones y páginas electrónicas).

\section{Trascendencia en las Encíclicas Sociales de la Iglesia Católica}

El primer concepto de dignidad de la persona humana, deviniendo en seguida la trascendencia del mismo concepto, aparece en la encíclica Pacem in Terris, proclamando 
que: "De igual manera, Dios creó el hombre a su imagen y semejanza ( $c f$. Gn 1, 26), dotándole de inteligencia y libertad, y le constituyó señor del universo..." (Juan XXIII, 1963, n. 3, final).

Más recientemente la Laborem Exercens continuaba: "El hombre es la imagen de Dios... todo ser humano refleja la acción misma del Creador del universo" (Juan Pablo II, 1981, n. 4). En la Rerum Novarum se decía que “...verán y comprenderán que todos los hombres han sido creados por el mismo Dios, Padre común; que todos tienden al mismo fin, que es el mismo Dios..." (León XIII, 1891, n. 20).

En el Concilio Vaticano II, la cuestión de la trascendencia se convierte en el eje de la visión ética de la dignidad humana. En él se constata la necesidad de no absolutizar un valor histórico limitado ni tampoco refugiarse en una pura trascendencia (Gaudium et Spes, n. 13).

Existe el principio de la dignidad humana cuando se aplica la cuestión de la libertad religiosa para todo ciudadano. Así, la Iglesia señala que ese principio no es solamente indicativo para la sociedad civil, pero es objetivamente normativo, en virtud de su naturaleza intrínseca. Conforme se manifiesta en el respectivo documento:

Además, los actos religiosos con que los hombres, partiendo de su íntima convicción, se relacionan privada y públicamente con Dios, trascienden por su naturaleza el orden terrestre y temporal. Por consiguiente, la autoridad civil, cuyo fin propio es velar por el bien común temporal, debe reconocer y favorecer la vida religiosa de los ciudadanos; pero excede su competencia si pretende dirigir o impedir los actos religiosos. (Dignitatis Humanae, 1965, n. 3)

Insiste todavía, en otro documento, que el Estado no será inducido por un principio engañoso o tendencioso porque dicho principio no es de la Iglesia Católica, no es del Estado ni tampoco es conclusión filosófica abstracta, pues:

No se equivoca el hombre al afirmar su superioridad sobre el universo material y al considerarse no ya como partícula de la naturaleza o como elemento anónimo de la ciudad humana. Por su interioridad es, en efecto, superior al universo entero; a esta profunda interioridad retorna cuando entra dentro de su corazón, donde Dios le aguarda, escrutador de los corazones, y donde él personalmente, bajo la mirada de Dios, decide su propio destino. (Gaudim et Spes, 1965, n. 14) 
La trascendencia de la dignidad de la persona humana, para la Iglesia Católica, tiene un doble origen religioso: el primero es la creación del hombre a imagen y semejanza de Dios, y el segundo es la posibilidad que tiene de ser rescatado en su dignidad perdida pues fue redimido por la muerte de Cristo. Una vez más se dice en la Pacem in Terris:

$\mathrm{Si}$, por otra parte, consideramos la dignidad de la persona humana a la luz de las verdades reveladas por Dios, hemos de valorar necesariamente en mayor grado aún esta dignidad, ya que los hombres han sido redimidos con la sangre de Jesucristo, hechos hijos y amigos de Dios por la gracia sobrenatural y herederos de la gloria eterna. (Juan XXIII, 1963, n. 10)

La trascendencia de la persona humana abarca dos dimensiones: la dimensión humana (de la filosofía, podría decirse) y la dimensión trascendente sobrenatural. En la encíclica Laborem Exercens, ambas apuntan hacia el mismo origen y al destino último de la dignidad de la persona humana: “...una convicción de la inteligencia... una convicción de fe. ...trata de expresar los designios eternos y los destinos trascendentes que el Dios vivo, Creador y Redentor ha unido al hombre” (Juan Pablo II, 1981, n. 4).

Si ya la fundamentación basada en la ley natural revela toda la dimensión de la dignidad humana, tanto más se la revela en su dimensión trascendente, pues ella tiene origen en el propio Dios, conforme se podrá constatar por la siguiente cita:

Sin embargo, este orden espiritual, cuyos principios son universales, absolutos e inmutables, tiene su origen único en un Dios verdadero, personal y que trasciende a la naturaleza humana. Dios, en efecto, por ser la primera verdad y el sumo bien, es la fuente más profunda de la cual puede extraer su vida verdadera una convivencia humana rectamente constituida, provechosa y adecuada a la dignidad del hombre... Es, por consiguiente, claro que la bondad de la voluntad humana depende mucho más de la ley eterna que de la razón humana. (Juan XXIII, 1963, n. 38)

La trascendencia es superior a la naturaleza, pues

El alma es la que lleva impresa la imagen y semejanza de Dios, en la que reside aquel poder mediante el cual se mandó al hombre que dominara sobre las criaturas inferiores y sometiera a su beneficio a las tierras todas y los mares... (León XIII, 1891, n. 39) 
Consecuencia de ello es que "El cristiano no puede admitir la que supone una filosofía materialista y atea, que no respeta ni la orientación de la vida hacia su fin último, ni la libertad ni la dignidad humanas" (Pablo VI, 1967, n. 39).

La fe cristiana siempre ha considerado el ser humano como un ser uni-dual, en que espíritu y materia se compenetran mutuamente, experimentando, ambos, precisamente de esa manera, una nueva nobleza. En efecto, “...el eros quiere remontarnos «en éxtasis» hacia lo divino, llevarnos más allá de nosotros mismos, pero precisamente por eso necesita seguir un camino de ascesis, renuncia, purificación y recuperación" (Benedicto XVI, 2005, n. 5).

En el debate filosófico y teológico, tales distinciones han sido, muchas veces, radicalizadas hasta el punto de ponerlas en contraposición: típicamente cristiano sería el amor descendiente, ablativo, o sea, el ágape; por otra parte, la cultura no cristiana, especialmente la griega, se caracteriza por el amor ascendiente, ambicioso y posesivo, o sea, por el Eros. Si se quisiera llevar hasta el extremo tal antítesis, la esencia del cristianismo quedaría desarticulada de las relaciones básicas y vitales de la existencia humana y constituiría un mundo independiente, considerado tal vez admirable, pero decididamente separado del conjunto de la existencia humana. En realidad, Eros y ágape - amor ascendiente y amor descendiente, trascendencia del amor divino- nunca se permiten separar completamente el uno del otro (Benedicto XVI, 2005, n. 6). Además:

En las culturas que circundan el mundo de la Biblia, la imagen de dios y de los dioses, al fin y al cabo, queda poco clara y es contradictoria en sí misma. En el camino de la fe bíblica, por el contrario, resulta cada vez más claro y unívoco lo que se resume en las palabras de la oración fundamental de Israel, la Shema: «Escucha, Israel: El Señor, nuestro Dios, es solamente uno» (Dt 6, 4). Existe un solo Dios, que es el Creador del cielo y de la tierra y, por tanto, también es el Dios de todos los hombres. (Benedicto XVI, 2005, n. 9)

Para confirmar y ahondar en ese principio, el Papa Francisco, en la encíclica Laudato Si, afirma:

En este universo, conformado por sistemas abiertos que entran en comunicación unos con otros, podemos descubrir innumerables formas derelación y participación. Esto lleva a pensar también al conjunto como abierto a la trascendencia de Dios, dentro de la cual se desarrolla. La fe nos permite interpretar el sentido y la belleza misteriosa de lo que acontece. $(2015$, n. 64$)$ 
Continúa el Papa, en la misma encíclica, explicando:

El ser humano, si bien supone también procesos evolutivos, implica una novedad no explicable plenamente por la evolución de otros sistemas abiertos. Cada uno de nosotros tiene en sí una identidad personal, capaz de entrar en diálogo con los demás y con el mismo Dios. La capacidad de reflexión, la argumentación, la creatividad, la interpretación, la elaboración artística y otras capacidades inéditas muestran una singularidad que trasciende el ámbito físico y biológico. (2015, n. 67)

El Documento de Aparecida (de la Conferencia Nacional de los Obispos del Brasil) presenta la trascendencia de la dignidad de la persona humana en su manifestación en los cambios culturales. "Entre os aspectos positivos dessa mudança cultural aparece o valor fundamental da pessoa humana, de sua consciência e experiência, a busca do sentido da vida e da transcendência” (2007, n. 35).

Otra fundamentación que se le da a la trascendencia de la persona humana es la creación. También dicha afirmación es constatada en el Documento de Aparecida:

A criação do homem e da mulher à sua imagem e semelhança é um acontecimento divino de vida, e sua fonte é o amor fiel do Senhor. Por conseguinte, só o Senhor é o autor e o dono da vida, e o ser humano, sua imagem vivente, é sempre sagrado, desde sua concepção, em todas as etapas da existência, até sua morte natural e depois da morte. O olhar cristão sobre o ser humano permite perceber seu valor que transcende todo o universo: 'Deus nos mostrou de modo insustentável como ama cada homem, e com isso lhe confere uma dignidade infinita'. (2007, p. 176)

No basta con que la Iglesia fundamente, proclame y defienda la dignidad humana si ella satisface solamente la dimensión natural, basada en la ley natural, en la naturaleza humana tan solo porque "...El hombre, por tener un cuerpo y un alma inmortal, no puede satisfacer sus necesidades ni conseguir en esta vida mortal su perfecta felicidad" (Juan XXIII, 1963, n. 59).

La trascendencia de la dignidad de la persona humana tiene también horizontes temporales, sociales. Por ello es que asegura Pablo VI en Populorum Progressio que:

Es un humanismo pleno el que hay que promover. ¿Qué quiere decir esto sino el desarrollo integral de todo hombre y de todos los hombres? Un humanismo 
cerrado, impenetrable a los valores del espíritu y a Dios, que es la fuente de ellos, podría aparentemente triunfar. Ciertamente, el hombre puede organizar la tierra sin Dios, pero «al fin y al cabo, sin Dios no puede menos de organizarla contra el hombre. El humanismo exclusivo es un humanismo inhumano». No hay, pues, más que un humanismo verdadero que se abre al Absoluto en el reconocimiento de una vocación que da la idea verdadera de la vida humana. Lejos de ser norma última de los valores, el hombre no se realiza a sí mismo si no es superándose. Según la tan acertada expresión de Pascal: «el hombre supera infinitamente al hombre». (1967, n. 42)

La consecuencia social de la trascendencia de la naturaleza humana es que, con ella, es posible llegar al humanismo integral, tal como se ha proclamado en la encíclica Populorum Progressio.

Amparar la trascendencia de la dignidad de la persona humana significa darle al ser humano respeto, considerando su esencia (Cruz \& Pozzoli, 2015, p. 87), especialmente, su creación a imagen y semejanza de Dios. Para comprender mejor tal "respeto al ser humano" se desarrollará esta investigación.

\section{Trascendencia del concepto de dignidad humana en el Derecho}

No se pretende hablar de la trascendencia en el Derecho, como lo hace la Doctrina Social de la Iglesia. Empero, no se puede olvidar que el bien común trasciende y realiza la dimensión de la historia. De ello se comprende que la dignidad no se reduce al bienestar económico, conforme a una visión historicista y materialista.

Es sabido que el camino histórico de la humanidad estuvo lleno de avances y retrocesos y que hizo del ser humano juguete en las manos de los dioses griegos, o de una parte indistinta de las comunidades en los Estados antiguos, al centro de sus propios pensamientos y realizaciones, entre ellos, el Estado y el Derecho (Barcelos, 2002, p. 104). La primera trascendencia de la dignidad de la persona humana en el Derecho es que ella no se crea por el derecho positivo, sino que es una realidad en sí misma y tiene fuerte lastre cimentado en el Derecho Natural.

En la Constitución de Alemania del período posterior a la Segunda Guerra Mundial, el concepto de dignidad de la persona humana se mostró como un valor absoluto que hace referencia directamente a la persona en sí y por sí, no pudiendo la ley infra-constitucional disponer sobre ella. 
Otra trascendencia de la dignidad de la persona humana es que, aun después de alcanzada en el plan individual, ontológico, de ley natural, ella trasciende hacia el orden social donde permanece como un valor trascendente, pero a la vez como un bien finito y cambiable. Tal heteronomía o elemento social de la dignidad le confiere una especie de trascendencia, pues sale de la esfera individual subjetiva para habitar el social objetivo. La universalidad de la dignidad humana también fundamenta a los derechos humanos.

...los derechos humanos se fundamentan en el reconocimiento de la dignidad del ser humano, y desde allí emerge su atractivo más poderoso: su universalidad y el consecuente respeto absoluto que suscitan (frente a la dignidad sólo cabe reconocimiento, no se trata de un atributo que el Estado conceda). Sin embargo, para que esto sea posible desde un punto de vista lógico, la dignidad tiene que encontrar, a su vez, un fundamento absoluto. (Cianciardo, 2020, p. 17)

Elementos de la historia auxilian en la difícil tarea de buscar responder a la cuestión del concepto de dignidad de la persona humana en el ámbito del Derecho, incluso porque dicha cuestión es abierta a estudios, posiciones, contribuciones, acuerdos y desacuerdos. Se entiende, sin embargo, que el Derecho puede y debe asumir tal causa en el sentido de, por lo menos, buscar en la sociedad la efectividad siempre más amplia de la promoción de la dignidad de la persona humana, constitucionalmente asegurada en muchos ordenamientos jurídicos, incluso en Brasil.

\subsection{El valor intrínseco de la dignidad de la persona humana y su trascendencia en la Historia y en el Derecho}

La cuestión del Dignitatis Hominis del derecho romano sigue presente en el concepto moderno de dignidad de la persona humana, pero no en el sentido de continuidad y sucesión, pues la sociedad actual exige una presuposición de valor intrínseco para la dignidad de la persona humana, principio formulado a partir de la tradición judeocristiana, por el Iluminismo y por el período posterior a la guerra de 1945 en adelante (Barroso, 2016, p. 14).

La Iglesia Católica en su Doctrina, especialmente en las encíclicas sociales, no pretende quitar a la persona humana de su realidad social, pero eso no quiere decir que la Iglesia esté satisfecha tan solo con la dimensión natural, basada en la ley natural, en la naturaleza humana. (Juan XXIII, 1963, n. 59).

Se entiende que la dignidad de la persona humana tiene también horizontes temporales, sociales, aunque no se limite a ellos. Siendo así, la consecuencia social 
de la trascendencia de la naturaleza humana es la de que, con ella, es posible llegar al humanismo integral en que Dios sea su fuente verdadera (Pablo VI, 1967, n. 42). Teniendo a Dios como su fuente verdadera en el humanismo integral, se puede llegar a una primacía de la persona a partir de su dignidad intrínseca.

...si los derechos se encuentran fundados de manera directa en la dignidad humana, una jerarquización o una ponderación de los derechos esconderá siempre una jerarquización o ponderación de la persona, una violación de su carácter de fin en sí mismo. (Cianciardo, 2020, p. 28)

Profundizando todavía en la trascendencia de la dignidad de la persona humana a lo largo de la historia, en la Doctrina Social de la Iglesia y en el Derecho, se puede considerar que subsiste una cuestión decisiva: ¿cómo puede ser percibido en los grandes acontecimientos como el Iluminismo, así como en la Declaración de los Derechos del Hombre y del Ciudadano, de 1789 en la Revolución Francesa, y en el período posterior a la Segunda Guerra Mundial?

La idea transmitida por el cristianismo en la antigüedad y en la Edad Media, en la religión y en la filosofía, acerca de la naturaleza trascendente de la dignidad de la persona humana, empezó a ser quebrantada por el pensamiento iluminista. Con su creencia fervorosa en la razón humana, el Iluminismo fue el responsable por dislocar la religiosidad del centro del sistema de pensamiento, sustituyéndola por el propio ser humano, en la secularización, en la sistematización, no obstante, y aun así, esas consecuencias desarrollaron la idea de dignidad humana y la preocupación por los derechos individuales del ser humano (Barcelos, 2002, p. 106).

La Declaración de los Derechos del Hombre y del Ciudadano de la Constitución Francesa de 1789, pone relieve en la trascendencia de la dignidad de la persona humana cuando proclama los derechos individuales como derechos válidos universalmente, ya que los seres humanos nacen y continúan libres e iguales en derechos. He ahí el inicio de la positivización de las ideas de la libertad inherente a los seres humanos y, por consiguiente, de derecho natural (Orsini, 2006, p. 48).

En la línea de una tradición ya formada en el pensamiento religioso y filosófico, la filosofía de Immanuel Kant tuvo gran influencia para la cuestión de la dignidad de la persona humana y su trascendencia. Es él quien presenta la formulación más consistente - particularmente compleja - de la naturaleza del ser humano y de sus relaciones consigo mismo, con el prójimo y con sus propias creaciones además de la naturaleza. Según Kant, el ser humano es un fin en sí mismo (dignidad ontológica) y no una función del Estado, 
de la sociedad o de la nación. El Derecho y el Estado deben de organizarse en beneficio de los seres humanos y no lo contrario (Barcelos, 2002, pp. 106-107).

Debido a que puede relativizar sus propios intereses, puede pretender que se respete su estatus absoluto de sujeto. Debido a que puede asumir libremente obligaciones, nadie tiene el derecho de hacerle esclavo, pues — como vio Kant correctamente - no puede tener ninguna obligación frente a su señor. Porque el hombre es, como ser moral, una representación de lo absoluto, por eso y sólo por eso, le corresponde aquello que llamamos 'dignidad humana'. (Spaemann, 1988, p. 23)

Además, Kant no tuvo la intención de forzar un concepto de trascendencia de la dignidad de la persona humana e imponerlo al Derecho y al Estado, sino que puso tales instituciones en la función de servidoras de la dignidad ontológica del ser racional. Dos son las variantes del ser humano: una, su dimensión social, material, cultural, económica y política; otra es la dimensión de la naturaleza humana, de la ley natural y del Derecho natural, que son intrínsecos al ser humano, que se trasluce en la libertad, en Dios y en el alma inmortal. La consecuencia es que “...los derechos humanos son derechos de la persona, pero de una persona abstracta e ideal, sino de una persona que sólo se puede comprender plenamente en un contexto cultural" (Cianciardo, 2020, p. 150).

Se puede decir que hay una interacción entre la Doctrina Social de la Iglesia Católica y la dogmática jurídica, cuando se hace referencia a la dignidad de la persona humana en su desarrollo, su trascendencia y concretización. Esto puede contribuir al encuentro de principios e indicaciones de acciones concretas que favorezcan la realización de las atribuciones tanto de la Iglesia como del Derecho en la efectividad de la dignidad de la persona humana, sea en ámbito espiritual, sea en el material, subjetivo u objetivo.

En cuanto a la dogmática jurídica, tiene ella función eminentemente social y, teóricamente, sólo desde esa perspectiva, cumplirá su función y su identidad, o sea, su dimensión material, concreta, social, cultural, económica y política.

Hay una convergencia cuando se afirman conjuntamente la ética civil y la moral cristiana. La aceptación del valor absoluto de la dignidad de la persona humana no debería constituir motivo de divergencias, sino que la oportunidad y la garantía de un diálogo respetuoso y fructífero entre ambas.

El valor absoluto de la dignidad de la persona humana puede ser considerado como convergencia, por parte de la ética civil y de la ética cristiana. Esto no se da para que 
haya una disputa, sino para establecer un campo común de actuación, de diálogo y de convivencia o convergencias.

Un auténtico fortalecimiento moral adquiere credibilidad cuando se sitúa en la búsqueda convergente por una historia basada en el valor absoluto de la dignidad de la persona humana.

Se puede percibir que el derecho natural y el derecho positivo tienen convergencias entre sí porque deberán asociarse para una justa aplicación de la ley puesta, es decir, el camino más lógico sería buscar subsidios en el derecho natural una vez que está el positivado en la Constitucional Federal del Brasil de 1988 en forma de principios.

\subsection{Discusión acerca de la trascendencia de la dignidad de la persona humana}

La discusión de la trascendencia de la dignidad de la persona humana, en este artículo, viene desarrollada en su aspecto histórico, conceptual y trascendental. Tal discusión está basada en tres elementos fundamentales: a) el valor de la trascendencia; b) los binomios fin/medio, absoluto/relativo y espiritual/material; c) histórico-cultural-dinámico.

a) El valor de la trascendencia

Parece necesario señalar el valor trascendente de la dignidad de la persona humana en que se encuentra una visión integral de la persona. Si, en el plano conceptual y teológico fue pensado un esquema diferente, a partir, particularmente, del Concilio Vaticano II, ya estaba sometida como razón motivadora. La Rerum Novarum sintetiza, de esa manera, las implicaciones políticas de la dignidad de la persona humana: "el hombre antecede el estado" (n. 6). El valor de los seres humanos es el signo standard bajo el cual las instituciones políticas y legales deben ser evaluadas. La política y la ley tienen que servir a las personas. La persona jamás tiene sencillamente un valor funcional, sino que tiene un valor trascendente; no hipotéticamente subordinado a cualquier otro fin. Aquí se sostiene la oposición a cualquier subordinación de la persona a un Estado absolutista.

El concepto mismo de dignidad humana es — como el de libertad - un concepto transcendental. Este concepto no indica de modo inmediato un derecho humano específico, sino que contiene la fundamentación de lo que puede ser considerado como derecho humano en general. (Spaemann, 1988, p. 15)

La defensa del valor trascendente de la persona condujo a Pío XI a la crítica de las organizaciones sociales asociadas al capitalismo liberal y al socialismo marxista en la 
encíclica Quadragesimo Anno (n. 46). Hay paralelismos entre el pensamiento de Marx y la visión de Pío XII acerca de las condiciones de los proletarios y el poder destructivo de la competencia desenfrenada. Pero el Papa refuta la lucha de clases y asocia la política socialista a un concepto materialista de persona subordinada a un fin impersonal. De hecho, claro está, el Papa no ha defendido una visión individualista de la persona. La vida social es constitutiva de la dignidad de la persona humana, porque las personas son siempre sociales, conforme enseña la encíclica Divinis Redemptoris.

En tal perspectiva, se comprende el corporativismo moderado y el socialismo de Pío XII. Subyacente a la propuesta, se encuentra la afirmación de la dimensión moral y constitutiva de las relaciones sociales que el pontífice percibe como tendencialmente anulada por el predominio de las relaciones de mercado, sin desconocer, todavía, que, en el origen, la emergencia de la economía de mercado exprime el deseo de autonomía y libertad de las dependencias feudales.

Esa discusión en torno al valor trascendente de la dignidad de la persona humana viene afirmada, pues, fuertemente ante las dictaduras fascista y nazi. El pontífice estaba interesado en asegurar la libertad de la Iglesia Católica en dichos regímenes y estaba dispuesto al compromiso cuando podría obtener concesiones para la Iglesia, sin embargo, fue reafirmada la oposición a todas las formas de absolutismo estatal.

En el abordaje de Pío XII, la visión de la sociedad en que la dignidad humana es respetada no es un paraíso anárquico ni tampoco un eschaton (el final o culmen) marxista, más bien es una tarea moral presente dentro de las condiciones y de los límites de la vida humana. Entonces, la realización del fin no se convierte en ideal imposible, pero sí en un imperativo moral sostenible. El respeto a la dignidad es fortalecido dentro y por medio de sus límites y condiciones. Aunque la dignidad tenga un valor trascendente, permanece un bien finito. Aunque la reivindicación moral por el respeto a la dignidad sea incondicionada, permanece una pretensión que es estructurada y condicionada por los límites y por las posibilidades de las personas en la sociedad: es estructurada por aquella forma finita de mutabilidad, que es la forma humana de la dignidad trascendente.

\section{b) Los binomios fin/medio, absoluto/relativo y espiritual/material}

En la discusión acerca de la trascendencia de la dignidad de la persona humana, Vidal cita el imperativo categórico kantiano como ética —el ser humano es y debe ser tratado como "fin" y jamás como "medio"- Para Kant, la bondad moral está en la actitud coherente con la realidad de la persona. Ahora bien, esa actitud se exprime con la categoría de fin/medio. En efecto, la categoría de fin/medio, la segunda fórmula del imperativo categórico, se puede comprender de la siguiente manera: “actúa de tal manera 
que siempre consideres la humanidad, tanto en su persona como en la de cualquier otro, como fin y jamás como puro medio".

El ser humano es una realidad "absoluta" y no "relativa". La persona tiene una dimensión moral porque no es un ser que se constituye como tal por la referencia a otro ser. El ser humano es de este modo un universo de carácter absoluto. No pretendemos negar que la persona tenga la instancia de apertura hacia los demás y a Dios, pero, aun en tal movimiento de apertura, no se puede perder la dimensión de centro; no se puede abandonar su carácter de absoluto.

Los dos grupos de categorías "fin/medio" y "absoluto/relativo" tienen gran capacidad no solo de asumir críticamente la dimensión ética de la persona, pero incluso de fundamentar todo el edificio de la moral. Por otro lado, tienen la huella del tradicional, porque fueron utilizadas dentro de la más genuina tradición del respeto al valor de la persona humana (Vidal, 1997, p. 163).

La discusión acerca de la trascendencia de la dignidad de la persona humana está relacionada a estos binomios: fin/medio, absoluto/relativo y espiritual/material. Eso porque el derecho trabaja con las dos realidades: una es la realidad histórico-cultural y la otra es la realidad espiritual (Sarlet, 2016, pp. 32-33).

La afirmación de la "humanización" de la dignidad de la persona humana está en la afirmación conjunta de la ética civil y de la ética moral cristiana. La aceptación del valor absoluto de la persona no constituye un motivo de disensión entre éticas laicas y religiosas, sino la oportunidad y la garantía de un diálogo fructífero entre ambas (Vidal, 1997, p. 165).

A afirmação conjunta do valor absoluto da pessoa por parte da ética civil e da ética cristã não é para disputar um terreno em litígio, mas para estabelecer um campo comum de actuação (sic), de diálogo e de convivência. Perante as divergências que nascem inevitavelmente das diversas cosmovisões e face às inevitáveis intransigências, fruto inadequado das divergências, é possível e necessário estabelecer um critério de unificação superior. Esse critério é o apelo ao valor absoluto da pessoa, a fim de construir uma história digna do ser humano. (Vidal, 1997, p. 165)

c) Histórico-cultural-dinámico

En la historicidad de la trascendencia de la dignidad de la persona humana, la discusión continúa en la cuestión del "derecho natural" y de la naturaleza humana universal. Sin embargo, la perspectiva histórica se encuentra, no pocas veces, "de parte" 
de la tradicional concepción "objetiva", que sostiene ser la naturaleza humana universal, dotada de dignidad, en cuanto fundada sobre el orden inmutable, establecido por Dios o sobre la semejanza con Dios mismo, raíz de la que derivan los derechos humanos de manera lógico-necesaria (Manzoni, 2010, p. 300).

Por otra parte, tal apelación al derecho natural, antes que fruto de una convención elaborada, parece intentar responder a la necesidad de universalidad y de comunicación concerniente a la sociedad contemporánea y a la que la Iglesia pretende responder, apelando a la naturaleza humana universal. El problema, no obstante, es si puede ser pensada y reconocida una naturaleza humana universal fuera o completamente anterior a sus determinaciones y expresiones históricas. Se pregunta si la dignidad del ser humano y los derechos humanos pueden ser pensados como instancias "objetivas, inviolables e inalienables", independientemente de la pluralidad de sus contenidos y del contexto histórico-social en los que sean proclamados (Manzoni, 2010, p. 300).

En otras palabras, la expresión "naturaleza humana" viene comprendida como un "principio normativo", un indicativo ético. De ahí se percibe que el término "naturaleza" no tendría el significado de algo puramente estático y fijo, sino que, de un conjunto estable y permanente de posibilidades, un esquematismo moral dinámico marcado por una inmanente "intencionalidad" abierta al bonum humanum, desde donde, todavía, se llega a que el concepto de naturaleza albergaría un elemento de perennidad, o sea, que trasciende a un elemento histórico-dinámico (Manzoni, 2010, p. 301).

Esa discusión sobre la trascendencia de la dignidad de la persona humana parece ser muy necesaria para esta investigación que busca, en esta comparación introductoria entre la Iglesia Católica y el Derecho - doctrina social y dogmática jurídica- encontrar algunos elementos comunes de convergencias y elementos de divergencias. Por eso, las convergencias y divergencias dependen mucho de la mirada del investigador y de sus cosmovisiones del tema investigado. Parece ser posible un criterio de unificación para entender los elementos de aproximación e interdependencia de las dos instituciones investigadas: la Iglesia Católica y la dogmática jurídica. Es el tema que se verá a continuación.

\section{La Relación entre la Doctrina Social de la Iglesia Católica y la Dogmática Jurídica en la Trascendencia de la Dignidad de la Persona Humana: el Derecho Natural}

En la Doctrina Social de la Iglesia Católica se pueden ver dos dimensiones: en la primera, se puede hablar de una dimensión humana (de la filosofía); y en la segunda de 
una dimensión trascendente sobrenatural. Ambas apuntan hacia el origen y al destino últimos de la dignidad de la persona humana: "convicción de la inteligencia", aunque "conquistada", en el sentido de ser también el resultado de un hacer, un actuar en la esfera social. Y la "convicción de fe".

El motivo es que la Iglesia — vale la pena observarlo desde ahora- cree en el hombre: ella piensa en el hombre y se dirige a él no sólo a la luz de la experiencia histórica, no sólo con la ayuda de los múltiples métodos del conocimiento científico, sino ante todo a la luz de la palabra revelada del Dios vivo. Al hacer referencia al hombre, ella trata de expresar los designios eternos y los destinos trascendentes que el Dios vivo, Creador y Redentor ha unido al hombre. (Juan Pablo II, 1981, n. 4)

No parece ser posible negar la dimensión conquistada de la dignidad de la persona humana ni el esfuerzo de la inteligencia a través de la evolución cultural e histórica, ya constatada en la humanidad, es decir, su dimensión social. Tampoco se puede negar la dimensión sobrenatural, o sea, la "convicción de fe", la búsqueda del ser humano por algo que trasciende lo puramente social.

\subsection{El derecho natural en la dogmática jurídica}

Así explica Lafer:

Certo é que o direito natural abrange uma elaboração doutrinária sobre o direito, mas apresenta, em suas vertentes de reflexão, vias muito variadas e diferenciadas, que não permitem atribuir-lhe univocidade, mas apenas algumas notas que permitem identificar; a ideia de imutabilidade — presume princípios que, por uma razão ou outra, escapam à história e, por isso, podem ser vistos como intemporais; a ideia de universalidade. Por isso, estes princípios são metatemporais. Ainda, os homens têm acesso através da razão, da intuição ou da revelação — por isso, os princípios do direito natural são dados e não postos por convenção. (1988, p. 36)

En la elaboración del derecho natural, dos planes se presentan: "É possível distinguir os seus dois planos: o ontológico e o deontológico. No primeiro, identifica-se o direito com o direito natural, no segundo, o direito natural aparece como um sistema universal e imutável de valores" (Lafer, 1988, p. 36). 
a) En el ontológico

En la Doctrina Social de la Iglesia Católica, esto quiere decir que la trascendencia de la dignidad de la persona humana merece respeto tal y como el ser humano. Significa considerar su esencia, especialmente por haber sido ser él creado a imagen y semejanza de Dios. "He aquí la fuente del verdadero humanismo integral - Dios" (Pablo VI, 1967, n. 42). En cuanto a la codificación del concepto de dignidad de la persona humana, tal hecho contribuyó a ordenar el caos del derecho privado, ante las políticas públicas y sociales. En otro aspecto, ofrece al Estado un instrumento eficaz de intervención en la vida social.

b) En el deontológico

En el Derecho, la dogmática jurídica aborda dos planes: ontológico y deontológico. La primera acepción abarca a la segunda, pues, en este caso, el ser del Derecho (ontológica) se constituye como deber del derecho positivo (deontología), en la medida en que se afirma que el derecho y hacer justicia son concebidos como actividades sinónimas. La segunda acepción, sin embargo, no abarca a la primera. En efecto, si se admite la existencia de valores universales e inmutables, no se niega la presencia de otros valores como los sociales, políticos y económicos que influyen en la realidad jurídica (Lafer, 1988, pp. 36-37). Así es proclamada la verdadera relación entre la Doctrina Social de la Iglesia Católica y la dogmática jurídica.

Sarlet así lo explica:

Tal teoria, além de não ser incompatível com a concepção ontológica da dignidade (vinculada a certas qualidades inerentes à condição humana), significa que uma proteção jurídica da dignidade reside no dever de reconhecimento de determinadas possibilidades de prestação, nomeadamente, a prestação do respeito aos direitos, do desenvolvimento de uma individualidade e do reconhecimento de um auto enquadramento no processo de interação social. (2015, p. 45)

La dignidad de la persona humana clama por una relación adecuada entre la Doctrina Social de la Iglesia Católica y la dogmática jurídica, pues necesita que dicha dignidad sea reconocida y desarrollada en su individualidad. Es menester que haya una protección humana cristiana y jurídica, capaz de ofrecer respeto a los derechos inherentes a la dignidad de la persona. 


\subsection{El bien común en la relación entre la Doctrina Social de la Iglesia Católica y la dogmática jurídica acerca de la trascendencia de la dignidad de la persona humana}

Primeramente, lo que se prescribe en la Doctrina Social de la Iglesia Católica es la dignidad, unidad e igualdad de todas las personas del cual deriva, antes que nada, el principio del bien común, el mismo que se debe relacionar cada aspecto de la vida social para encontrar pleno sentido. Se entiende por bien común: “...el conjunto de condiciones de la vida social que hacen posible a las asociaciones y a cada uno de sus miembros el logro más pleno y más fácil de la propia perfección..." (Gaudium et Spes, n. 26).

Así, el Compendio de la Doctrina Social de la Iglesia define el bien común de la siguiente manera:

El bien común no consiste en la simple suma de los bienes particulares de cada sujeto del cuerpo social. Siendo de todos y de cada uno es y permanece común, porque es indivisible y porque sólo juntos es posible alcanzarlo, acrecentarlo y custodiarlo, también en vistas al futuro. Como el actuar moral del individuo se realiza en el cumplimiento del bien, así el actuar social alcanza su plenitud en la realización del bien común. El bien común se puede considerar como la dimensión social y comunitaria del bien moral. (2006, n. 164)

El bien común en el Derecho - dogmática jurídica — debe ser entendido en las dos acepciones de la dignidad de la persona humana: primera, la posición especial del ser humano en el cosmos; segunda, la posición por él ocupada en la vida pública, es decir, el ser humano es diferente del resto de la naturaleza tanto por el motivo de ser el único animal racional, como por la manera activa con que se mueve en la vida pública, lo que le confiere un valor totalmente particular. Habría que mencionar, también, la ofensa a la dignidad de su naturaleza racional, ya que su dignidad personal mana de sus acciones realizadas en pro del bien común (Becchi, 2013, pp. 9-10).

Así también lo aclara Maritain acerca del bien común; aunque la dignidad humana sea algo intrínseco y propio del ser humano, el Estado y la Sociedad tienen el deber moral y ético de auxiliar su prevalencia. Recuerda el autor que "o bem comum é fundamental da autoridade, pois, a fim de conduzir uma comunidade de pessoas para o seu bem comum..., é mister que alguns em particular sejam encarregados dessa tarefa" (1967, p. 21), o sea, el bien común es un objeto social que necesita ser promovido, estimulado por alguien. 
Refiriéndose al bien común y a la dignidad de la persona humana en su relación con la Doctrina Social Católica y la dogmática jurídica en la trascendencia, se puede constar los sentidos absoluto y relativo.

Sarlet explica la premisa kantiana:

O homem e, duma maneira geral, todo o ser racional, existe como fim em si mesmo, não simplesmente como um meio para o uso arbitrário desta ou daquela vontade. Pelo contrário, em todas as suas ações, tanto nas que se dirigem a ele mesmo como nas que se dirigem a outros seres racionais, ele tem sempre de ser considerado simultaneamente como um fim. Portanto, o valor de todos os objetos que possamos adquirir pelas nossas ações é sempre condicional. (2016, p. 40)

En tales términos, la respuesta a las reivindicaciones a la dignidad de la persona humana está claramente asociada a la protección del bien común de todas las personas. Pero hay una serie de condiciones sociales que facilitan la realización del bien personal por parte de los seres humanos. Esas condiciones son realidades culturales y organizativas, y requieren una vida social que promueva el bien común temporal de todos, así como la convicción de su trascendencia.

Para demostrar la trascendencia jurídica de la dignidad de la persona humana, Maritain presenta dos planes: el espiritual y el temporal. Respecto del primero:

...a nossa atividade visa, como objeto determinante, à vida eterna, a Deus e às coisas de Deus, à obra redentora de Cristo à qual devemos servir em nós e nos outros. É o plano da Igreja. No segundo plano, de atividade, que é o plano do temporal, agimos como membros da Cidade terrena e como envolvidos nos negócios da vida terrena da humanidade. (2018, pp. 293-294)

En esta reflexión presentada, no importa el orden, puede ser intelectual o moral, científica y artística o social y política. Nuestra actividad, aunque está (si es honesta) dirigida hacia Dios como fin último, plantea en sí misma, como objeto determinante los bienes que no son la vida eterna, pero que conciernen, de manera general, a las cosas del tiempo, a la obra de la civilización o de la cultura. Es el plan del mundo (Maritain, 2018, pp. 293-294).

En el pensamiento de Maritain, estos dos planes de actividades son nítidamente distintos, pero no están separados. Ejemplifica, en el primer plan, en torno al orden de las cosas del mundo, esto es, el César (el terreno temporal); en el segundo plan, las cosas de 
Dios (Redención o espiritual). Para Maritain, estos dos órdenes permanecen nítidamente distintos, pero no se puede hacer esto: una mitad para las cosas del mundo y otra mitad para las cosas de Dios, una pagana y otra cristiana.

Los dos planes son también presentados en sus sentidos ontológico y deontológico, refiriéndose al derecho natural, o sea, el ser del derecho se constituye como deber ser del derecho positivo, en la medida en que el derecho y hacer justica son actividades concebidas como sinónimas. Esto, cuando se admite la existencia de valores universales e inmutables y no se niega la presencia de otros valores como los sociales, políticos y económicos que influyen en la realidad jurídica (Lafer, 1988, p. 37). Tal distinción y unidad de los dos planes sirve como base fundamental para la defensa de la dignidad de la persona humana en los planes metafísico y jurídico.

Para el derecho natural, en el derecho contemporáneo el orden moral está positivado, pero existe flexibilización de las interpretaciones, tomando en cuenta que los conceptos de moralidad acompañan a la evolución histórica de la sociedad. Es en ese sentido, la mezcla del derecho natural debe servir de base al derecho positivo, o subsidio, puesto que el derecho positivo envejece y el natural no. He aquí su trascendencia en la dignidad de la persona humana.

Para la ontología, se hizo necesario meditar sobre el sentido ontológico junto al sentido deontológico porque la primera acepción acabaría por abarcar a la segunda, pues, en tal caso, el propio ser del Derecho, o sea, la ontología, se constituye como deber ser del derecho positivo, o sea, la deontología, en la medida en el derecho, más precisamente en el caso concreto, y hacer justicia son concebidos como actividades sinónimas, tanto una como la otra. Aquí, el ontológico trae el sentido trascendente de la dignidad de la persona humana.

Finalmente, en relación a la Doctrina Social de la Iglesia Católica y a la dogmática jurídica, el bien común está conectado a la dignidad de la persona humana. Lleva a su protección, pues el bien común no es tan solo la suma de los bienes humanos, sino que tiene valor moral, el cual trasciende a todos los bienes y se realiza en el tiempo y en el espacio, o sea, en una época histórica.

\section{Conclusión}

La Doctrina Social de la Iglesia Católica sobre la trascendencia se apoya en un fundamento religioso para indicar que la dignidad humana se cimenta en el principio de que el ser humano fue creado a imagen y semejanza de Dios. Ese es el principio fundante y esencial para que se desarrolle y realice cualquier concepto o aplicación social de los 
derechos y deberes de la persona humana. Así, la Iglesia pone, en segundo plan, el aspecto filosófico de la dignidad de la persona humana, pero, aun así, resalta solamente aquel proveniente de la ley natural, por la que Dios puso en los seres humanos su condición de inteligencia y voluntad libres.

El Derecho, a su vez, privilegia y pone en primer lugar a las cuestiones históricas, la historicidad. No importa tanto lo que la filosofía clásica determina con sus principios. Todo lo que tiene sentido son las transformaciones de actitudes y pensamiento que la sociedad produce en la evolución de su tiempo y espacio que pasan a ser más importantes que la conceptuación ontológica de la dignidad de la persona humana.

Para el Derecho moderno, la cuestión filosófica de naturaleza y de ley natural significa poco para que se apunte hacia los fundamentos de la dignidad de la persona humana. Solamente el desarrollo histórico del pensamiento y de las costumbres de la humanidad es capaz y suficiente para fundamentar la cuestión de la dignidad humana. Basta con señalar que fue necesario el intervalo de tiempo desde las concepciones del Derecho Romano hasta las nuevas concepciones del Iluminismo y de la Revolución Francesa para que hubiera una evolución e implicancia efectiva acerca de la persona humana en la sociedad, principalmente occidental.

Acerca de la cuestión de la trascendencia del concepto de dignidad de la persona humana, tanto como de varios otros temas, la Doctrina Social de la Iglesia Católica y la dogmática jurídica se complementan y contribuyen para una perfecta y armónica comprensión de la dignidad de la persona humana, en la historicidad, en el concepto y en su trascendencia.

Por consiguiente, la Iglesia no niega la historicidad, pero no la considerada el móvil principal de la conducción de los principios de la dignidad humana. El Derecho, a su vez, no niega la importancia de la religión y de la filosofía para contribuir en el concepto $\mathrm{y}$ efectividad de los derechos fundamentales de la persona humana, consecuencias de su dignidad fundamental, sino que hace uso de ellas solamente para instrumentalizar la comprensión y no para constituir su esencia.

\section{Referencias}

Barcelos, A. P. (2002). A eficácia jurídica dos princípios constitucionais - O princípio da dignidade da pessoa humana. Renovar. 
Barroso, L. R. (2016). A Dignidade da Pessoa humana no Direito Constitucional Contemporâneo-A construção de um conceito jurídico à luz da jurisprudência mundial. Fórum.

Becchi, P. (2013). O Princípio da Dignidade Humana. Santuário.

Benedicto XVI. (2005). Carta Encíclica Deus Caritas Est. La Santa Sede. http://www. vatican.va/content/benedict-xvi/es/encyclicals/documents/hf_ben-xvi_ enc_20051225_deus-caritas-est.html

Cianciardo, J. (2020). La Cultura de los Derechos Humanos: Razón, Voluntad, Diálogo. UNAM. Biblioteca Jurídica Virtual. https://biblio.juridicas.unam.mx/bjv/ detalle-libro/6272-la-cultura-de-los-derechos-humanos-razon-voluntaddialogo

Conselho Episcopal Latino-Americano. (2009). Documento de Aparecida. Paulinas.

Concilio Vaticano II (1965). Constitución Pastoral Gaudium et Spes. La Santa Sede. http://www.vatican.va/archive/hist_councils/ii_vatican_council/documents/ vat-ii_const_19651207_gaudium-et-spes_sp.html

Concilio Vaticano II (1965). Declaración Dignitatis Humanae. La Santa Sede. http:// www.vatican.va/archive/hist_councils/ii_vatican_council/documents/vat-ii_ decl_19651207_dignitatis-humanae_sp.html

Cruz, A. A. F. \& Pozzoli, L. (2015). Princípio Constitucional da dignidade humana e o direito fraterno. E-Revista da Faculdade de Direito Santo Agostinho, 5, 8594. https://direito.fasa.edu.br/k/fasajus/12160887.pdf

Francisco. (2015). Carta Encíclica Laudato Si'. La Santa Sede. http://www.vatican.va/ content/francesco/es/encyclicals/documents/papa-francesco_20150524_ enciclica-laudato-si.html

Juan XXIII. (1963). Carta Encíclica Pacem in Terris. La Santa Sede. http://www.vatican. va/content/john-xxiii/es/encyclicals/documents/hf_j-xxiii_enc_11041963_ pacem.html

Juan Pablo II. (1981). Carta Encíclica Laborem Exercens. La Santa Sede. http:// www.vatican.va/content/john-paul-ii/es/encyclicals/documents/hf_jp-ii_ enc_14091981_laborem-exercens.html

Lafer, C. (1988). A reconstrução dos direitos humanos: um diálogo com o pensamento de Hannah Arendt. Companhia das Letras.

León XIII. (1891). Carta Encíclica Rerum Novarum. La Santa Sede. http://www.vatican. $\mathrm{va} /$ content/leo-xiii/es/encyclicals/documents/hf_1-xiii_enc_15051891_ rerum-novarum.html 
Manzoni, G. (2010). A dignidade da pessoa humana na Doutrina Social da Igreja. Teocomunicação - Revista de Teologia da PUCRS, 40(3), 289-306. https:// revistaseletronicas.pucrs.br/index.php/teo/article/view/8153

Maritain, J. (1967). Os Direitos do Homem. José Olympio.

Maritain, J. (2018). Humanismo integral: problemas temporais e espirituais de uma nova cristandade. Cultor de Livros.

Orsini, E. F. (2006). O princípio da dignidade humana: garantia constitucional. Fundação de Ensino Eurípedes Soares da Rocha.

Pablo VI. (1967). Carta Encíclica Popolorum Progressio. La Santa Sede. http:// www.vatican.va/content/paul-vi/es/encyclicals/documents/hf_p-vi_ enc_26031967_populorum.html

Pío XI. (1931). Carta Encíclica Quadragesimo Anno. La Santa Sede. http://www.vatican.

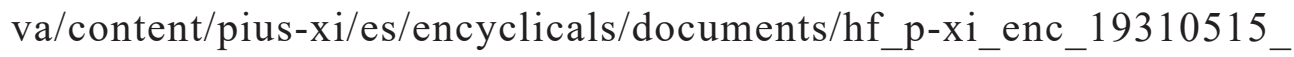
quadragesimo-anno.html

Pires, A. S. (2018). A Dignidade da Pessoa Humana: Historicidade, Conceito e Transcendência - Um Estudo a Respeito das Encíclicas Sociais Católicas em Comparação com a Dogmática Jurídica. UNIVEM.

Pontificio Consejo Justicia y Paz. (2006). Compendio de la Doctrina Social de la Iglesia. La Santa Sede. http://www.vatican.va/roman_curia/pontifical_councils/ justpeace/documents/rc_pc_justpeace_doc_20060526_compendio-dott-soc_ sp.html

Sarlet, I. W. (2009). Dignidade da pessoa humana e direitos fundamentais na constituição federal de 1988. Livraria do Advogado.

Sarlet, I. W. (2015). Dignidade (da pessoa) humana e direitos fundamentais na constituição federal de 1988. Livraria do Advogado.

Spaemann, R. (1988). Sobre el Concepto de la Dignidad Humana. Revista Persona y Derecho, Navarra, (19), 13-33. Recuperado de: https://revistas.unav.edu/ index.php/persona-y-derecho/article/view/32580.

Vidal, M. (1997). Dicionário de moral. Santuário. 
